\title{
INVERSE COMPUTATIONAL DETERMINATION OF JOHNSON-COOK PARAMETERS USING THE SHPB TEST APPARATUS
}

\author{
Anja Mauko*, Branko NeČemer, Zoran Ren \\ University of Maribor, Faculty of Mechanical Engineering, Smetanova ul. 17, 2000 Maribor, Slovenia \\ * corresponding author: anja.mauko@um.si
}

\begin{abstract}
The paper describes determination of the material parameters of the Johnson-Cook constitutive model of steel S235 JR sample material by applying the inverse computational methodology using the digital twin model of the SHPB. A quasi-static tensile testing of bulk material was conducted first to determine the base material parameters. This was followed by dynamic impact testing at two different strain rates using the SHPB. A digital twin computational model was built next in the LS-Dyna explicit finite element system to carry out the necessary computer simulations of the SHPB test. The inverse determination of strain hardening material parameter of Johnson-Cook model was done by using the Nelder-Mead simplex optimisation by comparing the measured and computed stress to time signals on incident and transmission bars. The obtained Johnson-Cook material parameters much better describe the sample material behaviour at very high strain-rates in computational simulations, if compared to the parameters derived by the classic, one-dimensional wave propagation Hopkinson procedure.
\end{abstract}

KEYwords: SHPB test apparatus, Johnson-Cook constitutive model, inverse determination, NelderMead optimization, computer simulations.

\section{INTRODUCTION}

Many studies have been carried out in the past to understand and thus enable predicting the material response under dynamic impact loading. The JohnsonCook (JC) constitutive model is most commonly used to describe the material strain-rate dependency in dynamic computer simulations. This paper describes an inverse computational method used to determine the strain-rate dependent parameters of the JC constitutive model for steel S235 JR [1]. The base quasi-static constitutive parameters were determined by classic quasi-static tensile testing. The strain-rate dependent material behaviour at different deformation rates was determined by using the Split Hopkinson Pressure Bar (SHPB) test apparatus [2]. The JC model was then validated by digital twin simulations of the SHPB.

\section{Materials And Methods}

\subsection{QUASI-STATIC TENSILE TESTING}

The quasi-static tensile tests were carried out on Instron 1255 tensile device equipped with the Aramis system for true stress - true strain determination. The testing samples were produced from steel S235 JR drawn wire with diameter of $6 \mathrm{~mm}$. The testing was conducted at room temperature $T=23^{\circ}$ and cross-head velocity of $0.5 \mathrm{~mm} \cdot \mathrm{min}^{-1}$, which corresponded to specific strain-rate $\dot{\epsilon_{0}}=3.06 \cdot 10^{-2} \mathrm{~s}^{-1}$. The obtained results in terms of Young's modulus, yield stress and tensile strength are listed in Table 1

\subsection{Dynamic impact SHPB testing}

The impact tests were performed on the SHPB test apparatus, shown in Figure 1. The SHPB set-up consist of three main parts: the loading device, bar components and data acquisition and recording system [3, 4. The role of loading device is to accelerate the striker to impact the incident bar, wherein the stress wave is produced. The nitrogen was used as the acceleration gas. The length of the striker is crucial for the amount of the energy produced by the impact. According to preliminary calculations, a $350 \mathrm{~mm}$ length of the striker was found to be sufficient. Two laser beam sensors, located directly before the impact of the striker and the incident bar were used to measure strikers velocity. The second part of the SHPB apparatus consists of the incident and the transmission bar with the sample sandwiched between them. The incident and transmission bar were each $1500 \mathrm{~mm}$ long with diameter of $20 \mathrm{~mm}$. Both bars and striker were made from the titanium alloy Ti6Al4V. The stress-strain waves were measured with the symmetrically attached foil strain-gauges on both bars with maximal sampling frequency of $5 \mathrm{MHz}$. Strain-gauges, arranged in Wheatstone quartal-bridge, had $2 \mathrm{~mm}$ of active length and resistivity $120 \Omega$. The strain gauges signal was amplified by the FE-H79-TA Fylde amplifier with gain of 100. The low-pass Butterworth filter was used to filter-out the high frequency noise recorded during the experiments.

The S235 JR steel samples were $3 \mathrm{~mm}$ long and of $6 \mathrm{~mm}$ diameter. Experimental results at two different strain-rates were required for determination of the JC 


\begin{tabular}{lll}
\hline Young's modulus & Yield stress & Tensile strength \\
$E[\mathrm{MPa}]$ & $R_{p 0.2}[\mathrm{MPa}]$ & $\sigma_{m}[\mathrm{MPa}]$ \\
\hline 192046 & 635 & 951 \\
\hline
\end{tabular}

TABLE 1. Material parameters obtained at quasi-static experiments.

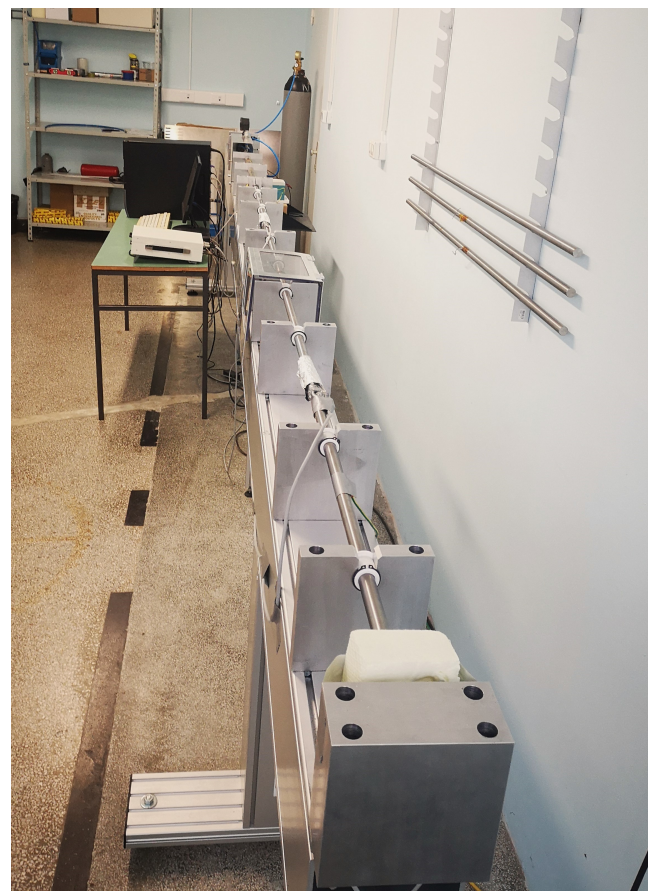

FiguRE 1. SHPB test apparatus at the University of Maribor.

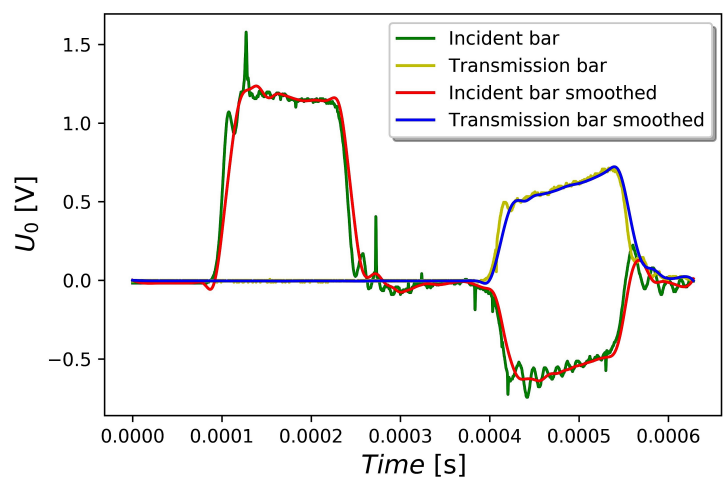

Figure 2. Comparison between filtered and unfiltered wave signal.

parameters. The first experiment was conducted at the striker speed of $v_{1}=17.05 \mathrm{~m} \cdot \mathrm{s}^{-1}$. The second experiment was conducted at the striker speed of $v_{2}=15.44 \mathrm{~m} \cdot \mathrm{s}^{-1}$. Figure 5 shows the results of both experiments in terms of stress signals recorded at strain gauges and the achieved strain-rate.

\subsection{JOHNSON-COOK MATERIAL MODEL}

The Johnson-Cook constitutive model allows to describe the effect of an isotropic kinematic hardening, strain-rate and temperature dependence of the material under the impact loading. It also considers the softening of the material that can occur due to adiabatic heating at higher deformation rates. One of the advantages of the JC model is its versatile use for different materials.

The basic equation of the Johnson-Cook constitutive model determines a current yield stress of the material as [5]:

$$
\begin{aligned}
& \sigma=\left(A+B \cdot \epsilon_{\mathrm{p}}^{\mathrm{n}}\right) \cdot\left(1+C \cdot \ln \left(\frac{\dot{\epsilon_{\mathrm{p}}}}{\dot{\epsilon_{0}}}\right)\right) \\
& \cdot\left(1-\left(\frac{T-T_{\mathrm{r}}}{T_{\mathrm{m}}-T_{\mathrm{r}}}\right)^{\mathrm{m}}\right)
\end{aligned}
$$

where $A, B, C, n$ and $m$ are model parameters, $\epsilon_{\mathrm{p}}$ is the effective plastic strain, $\frac{\epsilon_{\mathrm{p}}}{\epsilon_{0}}$ is the normalized plastic strain-rate, $T$ is material temperature, $T_{\mathrm{r}}$ is the room temperature and $T_{\mathrm{m}}$ is the melting temperature. Since all the experiments were conducted at room temperature, the equation 1 has been simplified to:

$$
\sigma=\left(A+B \cdot \epsilon_{p}^{n}\right) \cdot\left(1+C \cdot \ln \left(\frac{\dot{\epsilon_{\mathrm{p}}}}{\dot{\epsilon_{0}}}\right)\right) .
$$

The same simplification of the JC model has already been applied in articles [6] and [7, on the basis of which the temperature effect was neglected in this research. Parameter $A$ represents the quasi-static yield stress at room temperature as $A=R_{\mathrm{p} 0.2}$. The isotropic static hardening is captured by the parameters $B$ and $n$, which were determined on the base of the quasi-static response of the material, using equations given by Sobolev and Radchenko [5]. To determine the parameter of the dynamic hardening of material $C$ it was necessary to perform dynamic impact tests at two different strain rates and to apply the inverse computational methodology as described in the following chapters. It was previously determined that the application of classic, one-dimensional wave propagation Hopkinson procedure returns false dynamic hardening material parameter $C$, therefore inverse computational determination of parameter $C$ was proposed. The final obtained values of the JC material parameters are listed in Table 2

\subsection{Digital twin MOdel of the SHPB}

A digital twin model of the used SHPB test apparatus was built in the Ls-Dyna explicit finite element computer simulation system. The dimensions and parameters of the model were identical to the actual values observed on the SHPB test apparatus that was used to perform the experiments. 

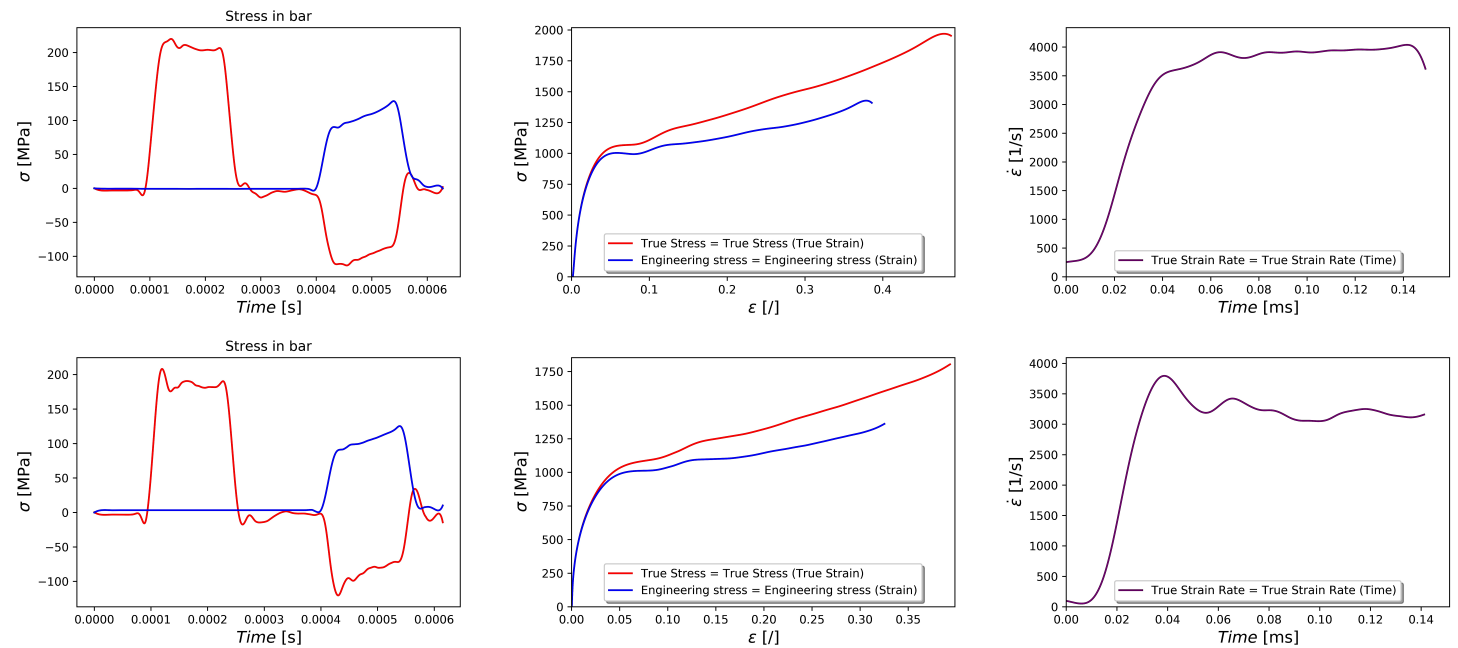

FiguRE 3. The experimental stress signals recorded at strain gauges and the achieved strain-rate obtained at two different striker velocities on SHPB test apparatus.

Top row: Strikers velocity $v_{1}=17.05 \mathrm{~m} \cdot \mathrm{s}^{-1}$, from left to right stress to time, stress to strain, strain rate to time diagram.

Bottom row: Strikers velocity $v_{2}=15.44 \mathrm{~m} \cdot \mathrm{s}^{-1}$, from left to right stress to time, stress to strain, strain rate to time diagram.

Only the basic components of the SHPB test apparatus were modelled, i.e the striker, incident and transmission bar and the sample between the bars. Due to double symmetry of the problem only a quarter of the overall model was used in simulations to reduce the simulation time, Figure 4 . The quarter model was validated by comparing its results with the results of the the full computational model of SHPB test apparatus.

A linear-elastic isotropic constitutive material model was used for the striker, incident and transmission bar. The Johnson-Cook constitutive material model was used to define the material properties of a specimen to incorporate the dynamic response of the material, with the model parameters $A, B, n$ and $C$, Table 2 The following contact conditions were defined: striker-incident bar, incident bar-sample, sample-transmission bar. All described contact were automatic surface to surface contacts. A dynamic friction coefficient of 0.1 was considered in the contacts between the incident bar-sample and sampletransmission bar, as it is proposed for the steel to titanium greased contact. At the striker-incident bar contact, a dynamic friction coefficient of 0 was defined.

Linear hexagonal finite elements of type C3D8R were used to spatially discretise the bars and the sample. The size of the finite elements was determined with the convergency analysis. The final mesh contained 12.206 finite elements.

The last step in creating a digital twin model was determination of boundary conditions. The SHPB model was embedded in such a way that only the movement in axial direction was enabled (z-direction, shown in Figure 4). The initial striker speed was equal to the speed of the striker observed in the experimental

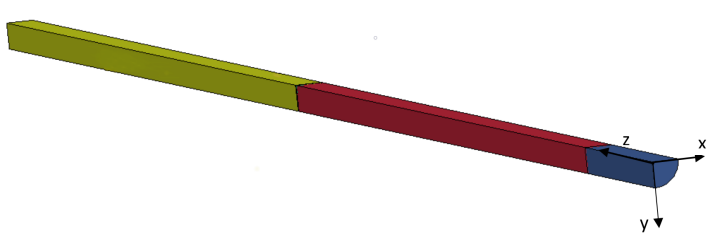

Figure 4. Digital twin model of the SHPB test apparatus.

testing on the SHPB test apparatus.

\subsection{INVERSE COMPUTATIONAL DETERMINATION OF PARAMETER C}

Dynamical hardening parameter $C$ was determined from the experimental results recorded at two different striker velocities by applying the inverse computational method using the optimization software OptiMax, featuring the Nelder-Mead simplex method [8]. The value of parameter $C$ was optimised to achieve the best fit of the digital twin computational results of stress signals with the experimental results. The best fit was at relative mean error (RME) of $10 \%$, determined using equation 3 were $\sigma_{1, \mathrm{i}}$ represents longitudinal experimental stress and $\sigma_{2, \mathrm{i}}$ longitudinal numerical stress. The final optimised value of parameter $C$ is listed in Table 2

$$
R M E=\frac{\sqrt{\frac{1}{N} \sum_{i=1}^{N}\left(\sigma_{1, \mathrm{i}}-\sigma_{2, \mathrm{i}}\right)^{2}}}{100}
$$

\section{Results}

The final optimized value of parameter $C$ was 0.31 [-]. The comparison of digital twin and experimental stress to time signals using the final JC material 

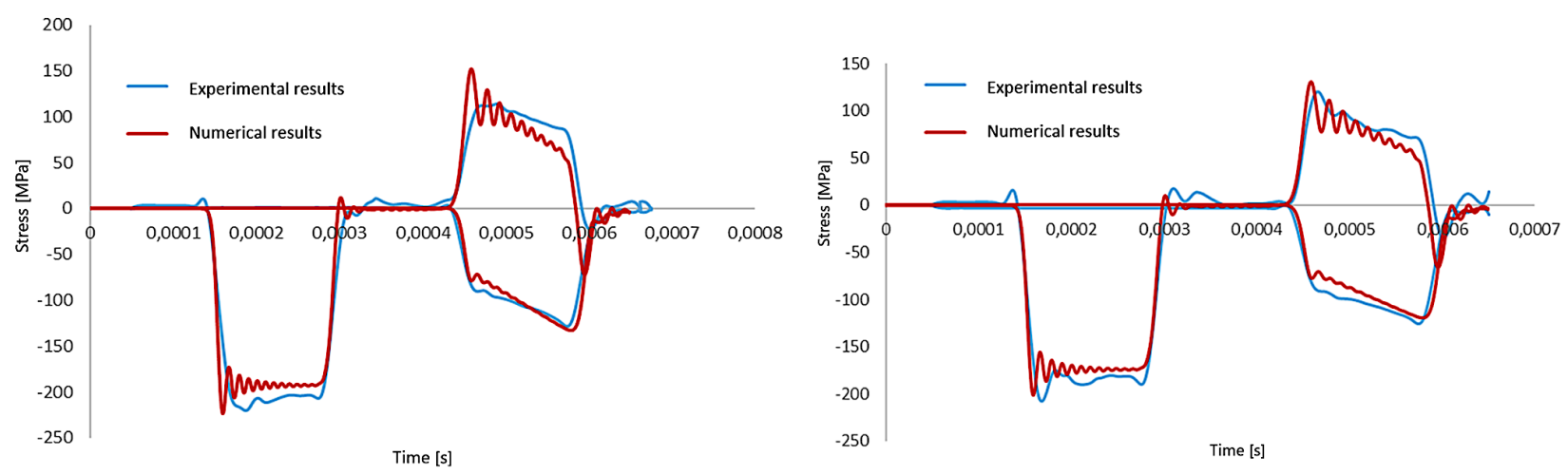

FiguRE 5. Comparison of experimental and numerical results. On the left figure is presented comparison between experimental and numerical results for strikers velocity $v_{1}=17.05 \mathrm{~m} \cdot \mathrm{s}^{-1}$. On the left figure is presented comparison between experimental and numerical results for strikers velocity $v_{2}=15.44 \mathrm{~m} \cdot \mathrm{s}^{-1}$.

parameters shows deviation of the reflected waves at $10.65 \%$ and for the transmitted waves at $27.89 \%$ at the striker velocity of $v_{1}=17.05 \mathrm{~m} \cdot \mathrm{s}^{-1}$, Figure 5 At the striker velocity $v_{2}=15.44 \mathrm{~m} \cdot \mathrm{s}^{-1}$ the deviation between reflected waves was $12.75 \%$ and for the transmitted waves $20.08 \%$. The average deviation was $17 \%$, which was acceptable for the purpose of the first study. To improve the final results, the future work will be focused on the strain-rate dependency of parameter $C$.

\begin{tabular}{lll}
\hline JC & material parameters & S235 JR steel \\
\hline$A$, & {$[\mathrm{MPa}]$} & 635 \\
$B$, & {$[\mathrm{MPa}]$} & 314 \\
$n$, & {$[-]$} & 0.75634 \\
$C$, & {$[\mathrm{MPa}]$} & 0.31 \\
\hline
\end{tabular}

TABLE 2. Final values of JC material parameters.

\section{Conclusion}

The paper describes the procedure for determining the material parameters of the Johnson-Cook constitutive model of steel S235 JR sample material by applying the inverse computational methodology using the digital twin model of the Split Hopkinson Pressure Bar test apparatus. A classic quasi-static tensile testing of sample steel material was conducted first to determine the base material parameters, i.e. the Young's modulus, the yield stress and the tensile strength. This was followed by dynamic impact testing at two different strain-rates using the Split Hopkinson Pressure Bar test apparatus. A digital twin computational model was built next in the LS-Dyna explicit finite element system to carry out the necessary computer simulations of the SHPB test. The inverse determination of strain hardening material parameter of Johnson-Cook constitutive model was done by using the Nelder-Mead simplex optimisation method by comparing the measured and computed stress to time signals on incident and transmission bars. The obtained Johnson-Cook material parameters much better describe the sample material behaviour at very high strain rates in computational simulations, if compared to the parameters derived by the classic, one-dimensional wave propagation Hopkinson procedure. However, a substantial deviation of results between experiments and digital twin was observed which necessitates further, more detailed research.

\section{ACKNOWLEDGEMENTS}

The authors acknowledge the financial support from the Slovenian Research Agency (research core funding No. P20063).

\section{REFERENCES}

[1] A. Mauko. Inverzna numerična določitev parametrov Johnson-Cook konstitutivnega modela jekla z uporabo SHPB preizkuševališča 2018. https:

//dk.um.si/Dokument.php?id=129259\&lang=eng.

[2] W. Chen, B. Song. Split Hopkinson (Kolsky) Bar Design, Testing and Application, vol. 39. 2008.

[3] L. Adanič, B. Nečemer, M. Frankovič. Konstruiranje, gradnja in umerjanje shpb preizkuševališča 2015. https: //dk.um.si/Dokument . php?id=80745\&lang=eng

[4] B. Nečemer. Numerično modeliranje in validacija SHPB-preizkuševališča 2017. https: //dk.um.si/Dokument.php?id=116571\&lang=eng

[5] A. Sobolev, M. Radchenko. Use of Johnson-Cook plasticity model for numerical simulations of the SNF shipping cask drop tests. Nuclear Energy and Technology 2(4):272-276, 2016. DOI:10.1016/j.nucet.2016.11.014.

[6] D. N. Zhang, Q. Q. Shangguan, C. J. Xie, F. Liu. A modified Johnson-Cook model of dynamic tensile behaviors for 7075-T6 aluminum alloy. Journal of Alloys and Compounds 2015. DOI:10.1016/j.jallcom.2014.09.002

[7] Z. Xie, Y. Guan, J. Lin, et al. Constitutive model of 6063 aluminum alloy under the ultrasonic vibration upsetting based on Johnson-Cook model. Ultrasonics 96:1-9, 2019. DOI:10.1016/J.ULTRAS.2019.03.017

[8] M. Borovinšek. Optimax USER'S MANUAL v0.6.3, 2017. http://lace.fs.uni-mb.si/wordpress/ borovinsek/wp-content/uploads/sites/6/2017/01/ Optimax-USERS-MANUAL-v0.6.3.pdf. 